DOI: http://dx.doi.org/10.18203/2320-1770.ijrcog20160417

Case Report

\title{
An unusual case of labial fusion
}

\section{Neha V. Bhave*, P. K. Shah, Hemangi Chaudhari}

Department of Obstetrics \& Gynaecology, Seth G.S. Medical College and King Edward Memorial Hospital, Parel, Mumbai, Maharashtra, India

Received: 14 December 2015

Accepted: 08 January 2016

\section{*Correspondence:}

Dr. Neha V. Bhave,

E-mail: nehabhave17@gmail.com

Copyright: (C) the author(s), publisher and licensee Medip Academy. This is an open-access article distributed under the terms of the Creative Commons Attribution Non-Commercial License, which permits unrestricted non-commercial use, distribution, and reproduction in any medium, provided the original work is properly cited.

\section{ABSTRACT}

Labial fusion is sealing of labia minora in midline. It is also known as Labial adhesion or Labial agglutination or synechia vulvae. This condition is common in pre-pubertal females when estrogen levels are low and commonly resolves spontaneously post-puberty. Usually asymptomatic and typically treated conservatively. Medical treatment includes use of estrogen cream or betamethasone cream. Surgical treatment rarely required, if not responding to medical treatment or dense adhesions. This case report is unusual as it presented in a post-pubertal female and which needed surgical management.

Keywords: Labial adhesion, Labial fusion, Labial agglutination, Synechia vulvae

\section{INTRODUCTION}

Labial fusion is when the lips of labia minora around the entrance to the vagina become fused together or covered with a fleshy membrane. The membrane usually completely seals the vaginal opening, leaving a very small gap at the front through which urine passes. It is also known as labial agglutination or labial adhesion. Labial fusion is affects $2-5 \%$ of babies and young girls, most commonly seen between 1-2 years of age. ${ }^{1}$

\section{CASE REPORT}

A 23 year, unmarried female, came to gynecology outpatient department with complains of decreased flow during menses and pain in abdomen on and off since 12 years. The pain was since menarche which was spasmodic in nature and was associated with menses. A past history of fall on perineum at 12 years of age and wound over labia was sutured under local anesthesia was noted. After the intervention a pin point opening over perineum had developed through which she would urinate as well as menstruate. Her complains had developed after the incident. There was no history of sexual abuse or no complains of irritation or allergic rash over labia in past. No other bowel or bladder complains.

Her general and systemic examination was normal. On abdominal examination, her abdomen was soft. On local examination of genitals, labia majora was normal and labia minora was fused in midline. Urethral opening was not visualized in anatomical place. Perineum was normal. No scar visible. A small $0.5 \mathrm{~mm}$ circular opening visualized near fourchette (Figure 1). On per rectal examination, uterus was normal in size, anteverted. Bilateral fornices were free and non-tender.

All routine investigations needed for surgery were done and noted normal. Ultrasound showed uterus anteverted and normal size, bilateral ovaries were normal. As exact anatomy behind the fused labia could not be made out, a vaginogram with simultaneous micturating cystourethrogram was done. The film (Figure2) showed bladder and urethra both visualized and normal. The 
vaginal pouch is opacified and seen separate from bladder.

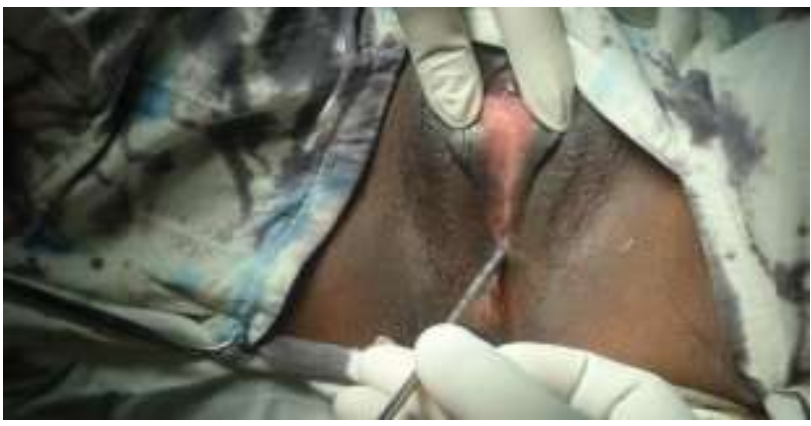

Figure 1: A small Hegar's dilator is passed through the circular opening near fourchette.
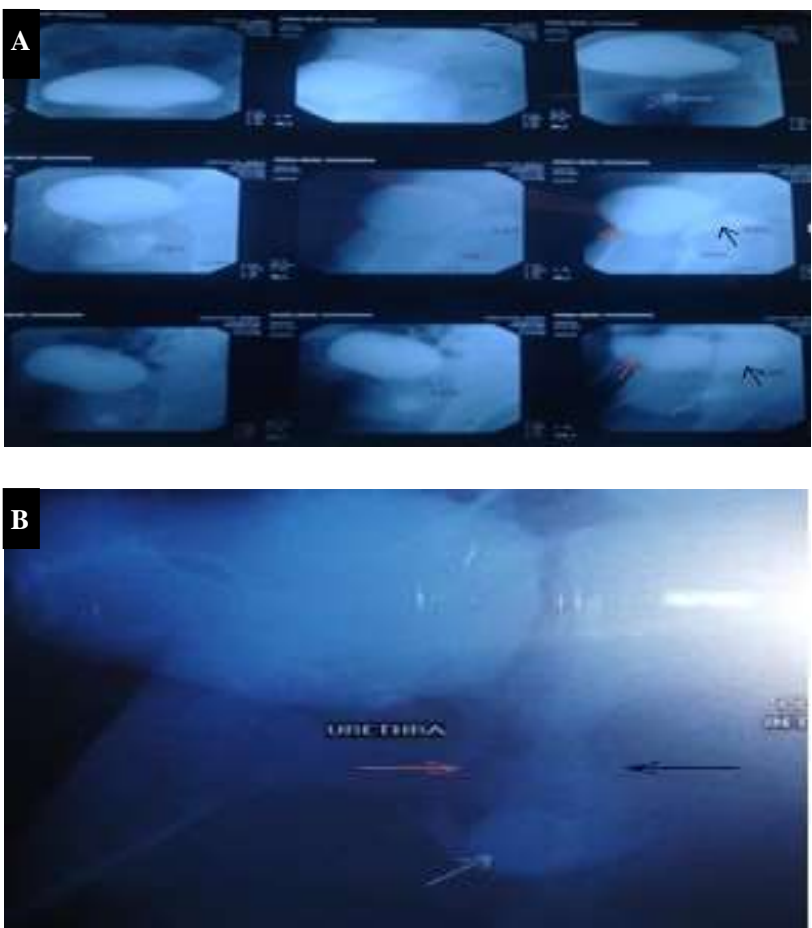

Figure 2: (A): A Complete film of the Micturating cystourethrogram with vaginogram.

(B): Magnification of last image in the film. The red arrow shows urethra and black arrow shows vagina.

The blue arrow shows the inflated bulb of Foley's catheter.

A decision for Labia minora reconstruction with urethroplasty was taken with multidisciplinary approach.

The fused tissue from introital opening dissected layer by layer and opened anteriorly (Figure 3). Anterior wall of vagina was seen (Figure 4). Normal rugosity were maintained. Sharp and blunt dissection was carried upwards to visualize the urethral opening (Figure 5). The urethral meatal opening was seen $1 \mathrm{~cm}$ below the clitoris. A silicone catheter was passed through it (Figure 6). The final appearance of vagina inside which healthy cervix is visualized with a catheter in urethra (Figure 7).
Post-operative course was uneventful. An antibiotic ointment and estrogen cream for local application was given. Catheter was removed on day 7. Patient passed urine uneventfully. On follow up, patient was day 4 of menses and had no complain of pain with normal flow.

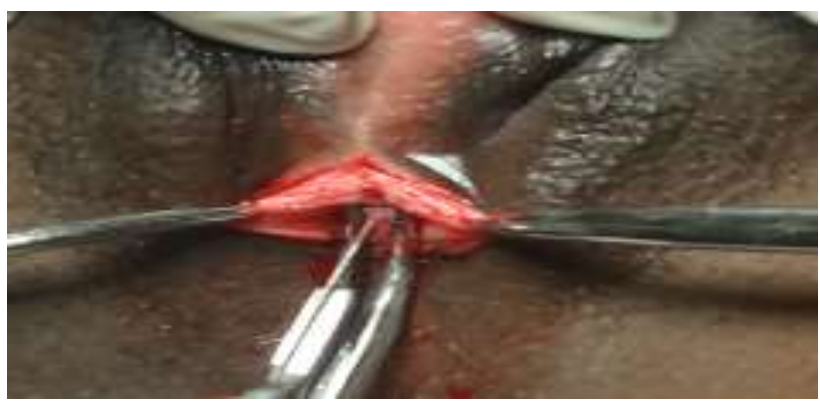

Figure 3: Layer by layer dissection.

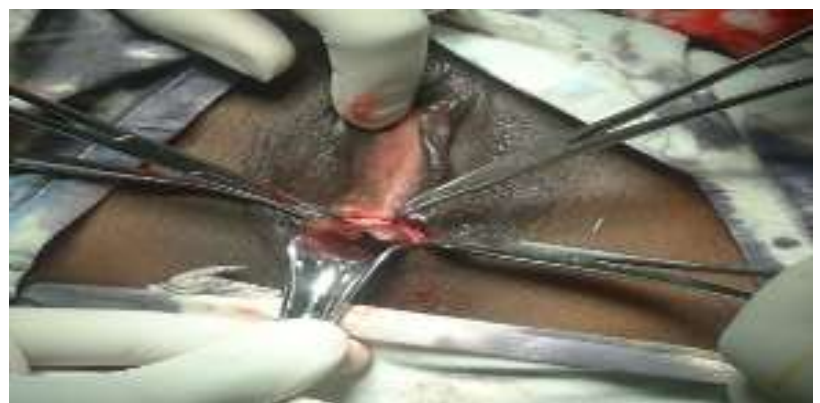

Figure 4: Visualization of anterior vaginal wall.

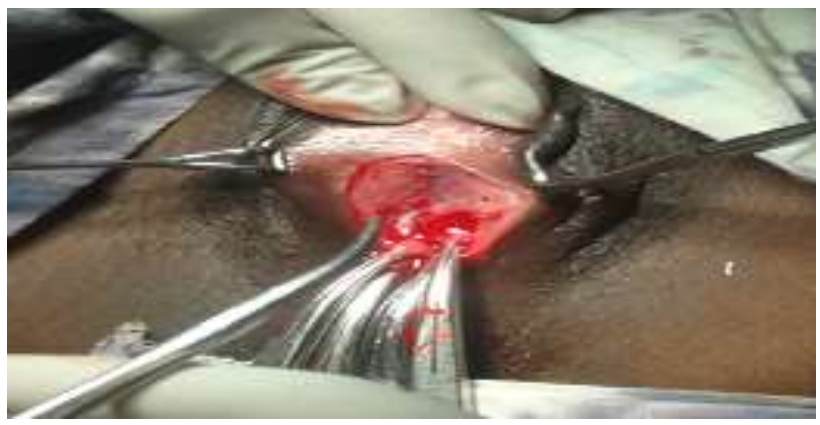

Figure 5: Dissection for visualization of urethra.

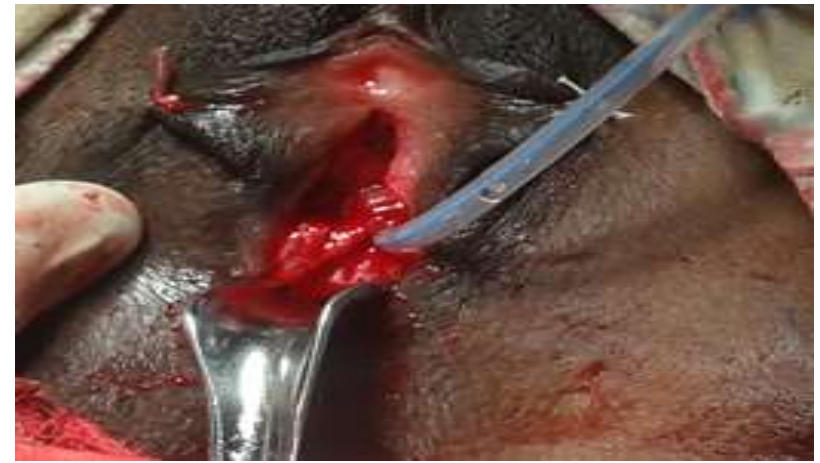

Figure 6: Silicon catheter insertion in urethra. 


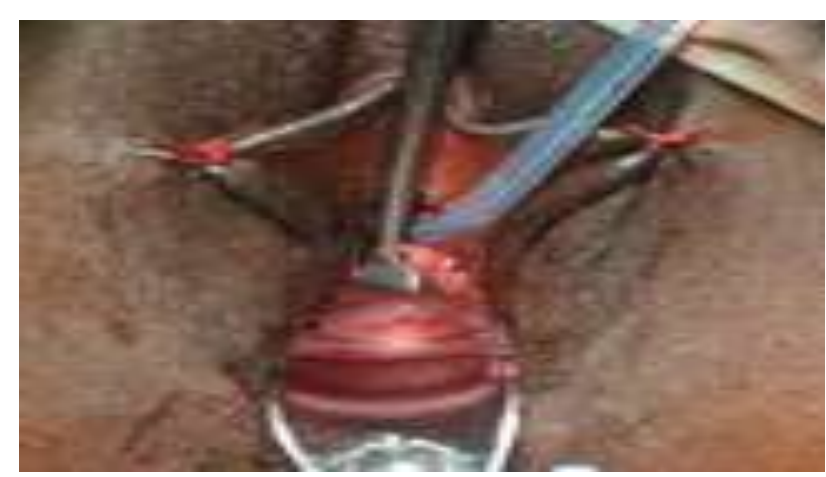

Figure 7: Visualization of healthy cervix with catheter in urethra.

\section{DISCUSSION}

Labial adhesions are more common during nappy years, in an age group of 3 months to 3 years. The outer surface of the labia minora, lined by squamous epithelium, is thin and delicate. Irritation and inflammation can cause the outer skin to become exposed and raw which then heal together in much the same way as any skin cut might heal. The causes of inflammation or irritation of skin of labia minora can be faeces, urine, strong perfumed soaps, bubble baths, vulvovaginitis, atopic dermatitis, pinworms, labial injuries or sexual abuse. ${ }^{2}$ Usually, the labia start to fuse at the bottom end (posterior fourchette) and work up towards the clitoris. Low estrogen levels are thought to contribute to development of such adhesions. The condition usually resolves during puberty because the effect of estrogen changes the cells that line the genitals.

It is generally asymptomatic but can also present with complains of urine pooling in vagina on voiding followed by leakage from the vagina on standing after voiding or changes in the direction of urine stream. In about $20 \%$ of girls, asymptomatic bacteriuria develops and up to $40 \%$ experience symptomatic urinary tract infections.

If there are no complains or complications, the adhesions do not need treatment. The medical treatment of labial adhesions for young girls is application of topical estrogen cream directly on the labia minora. Conjugated estrogen cream or estradiol vaginal cream (0.01\%) applied to the adhesions 1-2 times daily for several weeks until the adhesion resolves. ${ }^{3}$ Adverse systemic effects from estrogen application are rare and include local irritations, vulvar pigmentation, and breast enlargement. While there are no available randomized controlled trials, the success rate of such creams is reported in the literature to be close to $90 \%$ with minimal recurrence. . $^{4-6}$ An alternative line of treatment is topical $0.05 \%$ betamethasone cream. One to three courses of twice daily betamethasone for 4-6 weeks have showed promising results. $^{7}$ A retrospective study comparing medical treatment of estrogen alone, betamethasone cream alone or combination of both for 2 to 4 weeks showed no significant differences among the group. ${ }^{8}$
Adhesion if dense or not responding to medical treatment may require surgical management. The adhesions are divided by gentle traction or running a sound along the fusion line. ${ }^{9}$ Once the labial adhesions separate, emollient such as antibiotic ointment applied several times a day to prevent repeat adhesion formation.

The recurrence rate of labial adhesions is $11-14 \% .^{10}$ Usually recurring adhesions especially post-surgical are denser and less likely to resolve with conservative line of management. The surgical techniques include use of amniotic membrane, rotational skin flaps with varying rate of success. ${ }^{11,12}$

\section{CONCLUSIONS}

This is a rare case with fused labia minora in post pubertal girl that developed post-trauma to genitals which required surgical management.

\section{Funding: No funding sources \\ Conflict of interest: None declared \\ Ethical approval: Not required}

\section{REFERENCES}

1. Leung AK, Robson WL, Tay-Uyboco J. The incidence of labial fusion in children. J Paediatr Child Health. 1993;29(3):235-6.

2. McCann J, Voris J, Simon M. Labial adhesions and posterior fourchette injuries in childhood sexual abuse. Am J Dis Child. Jun 1988;142(6):659-63.

3. Goldman RD. Child health update: estrogen cream for labial adhesion in girls. Can Fam Physician. 2013;59(1):37-8.

4. Capraro VJ, Greenberg H. Adhesions of the labia minora. A study of 50 patients. Obstet Gynecol. 1972;39(1):65-9.

5. Aribarg A. Topical oestrogen therapy for labial adhesions in children. Br J Obstet Gynaecol. 1975;82(5):424-5.

6. Khanam W, Chogtu L, Mir Z, Shawl F. Adhesion of the labia minora-a study of 75 cases. Obstet Gynecol Surv. 1978;33(5):364-5.

7. Myers JB, Sorensen CM, Wisner BP, Furness PD, 3rd, Passamaneck M, Koyle MA. Betamethasone cream for the treatment of pre-pubertal labial adhesions. J Pediatr Adolesc Gynecol. 2006;19(6):407-11.

8. Eroglu E, Yip M, Oktar T, Kayiran SM, Mocan H. How should we treat prepubertal labial adhesions? Retrospective comparison of topical treatments: estrogen only, betamethasone only, and combination estrogen and betamethasone. J Pediatr Adolesc Gynecol. 2011;24(6):389-91.

9. Michala SM. Fused labia: a paediatric approach. The Obstetrician and Gynaecologist. 2009;11:261-4.

10. Soyer T. Topical estrogen therapy in labial adhesions in children: therapeutic or prophylactic? Journal of 
Pediatric and Adolescent Gynecology. 2007;20:2414.

11. Lin YH, Hwang JL, Huang LW, Chou CT. Amniotic membrane grafting to treat refractory labial adhesions postpartum - a case report. The Journal of Reproductive Medicine. 2002;47:235-7.

12. Johnson N, Lilford RJ, Sharpe D. A new surgical technique to treat refractory labial fusion in the elderly. American Journal of Obstetrics and Gynecology. 1989;161:289-90.

Cite this article as: Bhave NV, Shah PK, Chaudhari H. An unusual case of labial fusion Int J Reprod Contracept Obstet Gynecol 2016;5:572-5. 